working party asks that local authorities be statutorily required "to provide social work support for the health services" and that area health authorities should "provide medical and nursing support for local authority social services." This has already been written into the new Act, but it will require much more than a fine-sounding statute to provide the necessary staff, facilities, and co-operation to ensure that the correct social support gets to the right patient at the right time.

The B.M.A. welcomed the Government's decision to include the School Health Service in the reformed N.H.S. and the report explores the matter in some detail. Nevertheless, local authority organizations have opposed this move and judged by some dissenting paragraphs from three local government representatives (one a dental officer) there is st.ll unease. They raise doubts about the extent of co-operation and "the degree of priority which the N.H.S. will be able to accord to the school health service." It will be up to doctors and nurses in the Health Service to allay these fears.

These notes of disagreement are a warning of potential hazards ahead. It will be the task of joint consultative committees, to be set up by each A.H.A. and the corresponding local authority(ies), to anticipate such hazards by planning and co-operation. This is important because, in giving helpful practical advice on their functions, the Working Party has decided that it is "unnecessary to provide formal machinery for resolving disputes"-either in the committees or between authorities. The work of these advisory committees should be helped by the proposal that any recommendation to their parent authorities should be made public. Too often the gestation of local authority and N.H.S. dec:sions affecting the community occurs behind closed doors and any publicity should be welcomed.

Traditionally environmental health has been a local government preserve and many authorities and their medical staff have some outstanding achievements to their credit in this field of medicine. It was not unexpected, therefore, that local authority organizations should resist the removal of this work from their orbit. Certainly, the chapter contributed by the suboommittee looking at environmental health manages to convey a feeling of disapproval for the new arrangements. Local authorities obviously do not relish the idea of a doctor working for the area health authority providing them with medical advice-despite their custom of split appointments and part-time medical advice. Thus after balancing the arguments for seeking general medical advice from an A.H.A. against the employment of a medical adviser with a detailed contract the Working Party takes "the middle way" and suggests secondment of a a doctor from the A.H.A. at the invitation of the local authority. This type of appointment breaks now ground and it may take some time for the arrangements to shake down. Nevertheless, public health doctors will criticize the lack of any proposal for a statutory cbligation on local Authorities to seek advice from the N.H.S. - a failure, unfortunately, that applies to all medical aspects of local authority work.

Sir Keith Joseph and his colleague in Wales, Mr. Peter Thomas, have commended this report to the "existing and new health and local authorities." It will be followed by more recommendations, as the "Collaboration Working Party" is like"y to survive beyond April 1974. This news may bring a groan from those already stunned by the avalanche of official papers. But relations between reorganized local gorernment and a changed Health Service may be quite touchy for a while as both try to find their way in new territory. Patients will suffer if collaboration starts off on the wrong foot so this report and any future comments deserve more than just a passing glance from doctors.

1 National Health Service Reorganisation Bill, London, H.M.S.O., 1973.

2 Department of Health and Social Security, Welsh Office, $A$ Report from the Working Party of Collaboration between the N.H.S. and Local Government on its Activities to the End of 1972, London, H.M.S.O., 1973. 3 British Medical fournal, 1971, 3, 439.

4 British Medical fournal, 1971, 4, 691

Department of Health and Social Security, National Health Service Reorganisation, Consultative Document, London, 1971.

- British Medical fournal, 1972, 3, 248.

7 British Medical fournal, 1973, 2, 623.

\section{Childhood Obesity and Carbohydrate Intolerance}

Obesity in childhood has emerged as an important challenge to paediatricians and family doctors. Its consequences are complex, and the serious effects may show overtly only in adult life in an increased monbidity and mortality rate. For too long there has been failure to recognize the relationship of obesity in childhood to the problems of the overweight adult. Degenerative vascular disease, job problems, and insurance premiums seem far removed from the overweight infant, toddler, or school child.

Recently attention has been focused on the tendency of some young infants to gain weight too quickly. ${ }^{1}$ This has been attributed to overfeeding, which in part is the result of the unduly early introduction of cereals. With the excessive intake of calories there is evidence of simultaneous excessive intake of sodium. ${ }^{2}$ The determinant of the final number of fat cells we have may be the number required for storage in early life. J. Hirsch and P. W. Han ${ }^{3}$ showed that forced feeding of rats during infancy permanently increased fatness and the number of fat cells. Thus we may be programmed for appetite at this early stage, and this programming could be set by both a central mechanism and a demand by peripheral cells. Studies of the number and size of fat cells have y:elded information suggesting that overfeeding should be avoided in the first years of life, when the numbers of fat cells are finally determined. ${ }^{4}$ When a person loses weight after this time, fat cells do not disappear; they simply decrease in size.

Up to $80 \%$ of obese children are reported to remain obese as adults, ${ }^{56}$ and $\mathrm{E}$. E. Eid ${ }^{7}$ showed that excessive weight gain in the first six weeks of life was related to being overweight at 6 to 7 years of age. Changes in carbohydrate metabolism in the obese have been extensively studied. The effect of insulin on glucose uptake by the subcutaneous tissue of the forearm is attenuated in obese people, ${ }^{8}$ and the enlarged adipocytes obtained from the obese are relatively insensitive to insulin in terms of glucose uptake and utilization. 9 The secretion of glucagon in the obese is also altered. ${ }^{10}$ M. M. Martin and A. L. A. Martin ${ }^{11}$ have recently published the results of a study of the relationship of obesity in childhood to carbohydrate tolerance in childhood. They investigated a group of 42 fat children and 30 of normal weight by performing five-hour oral glucose tolerance tests and also analysing samples of plasma for growth hormone and immunoreactive insulin. Their results showed chemical 
diabetes to be present in $12(29 \%)$ of the unselected obese children. In addition, a further $11(26 \%)$ had impairment of glucose tolerance as judged by hyperinsulinaemia with two or more plasma insulin levels greater than $100 \mu \mathrm{U} / \mathrm{ml}$. Though glucose tolerance of 11 of these patients was within the normal distribution, it was nevertheless impaired in comparison with the levels in the children of normal weignt and obese children with normal insulin levels. Thus half the obese children studied had varying degrees of diminished carbohydrate tolerance. While the interpretation of hyperinsulinaemia in this method of study may be open to debate, the distorted glucose tolerance profile of half the obese children is fairly good evidence of the disadvantage that obesity confers on the fat child.

Thus we are left not with the question of-To treat or not to treat, but How to treat? It seems likely that treatment should be started at an early age if it is to have long-term success. Experience suggests that motivation by both parents and child is important. As well as inducing controlled loss of weight the aim of treatment is to recondition the child's eating habits for the future. Unfortunately at the present time our results of treatment have not been encouraging and the prognosis is poor for the child with established obesity. We must, therefore, explore more energetically the avenues of prevention, and here family doctors and those in child welfare clinics are in the best position to warn and advise parents. From an early age children should avoid the sweet eating habit and this caveat includes crisps and peanuts. Giving sweets to children as an act of kindness is far from being kind. The Tanner and Whitehouse centile charts ${ }^{12}$ for recording weight should replace the usual clinic card. Too rapid an increase in weight is detected more easily when plotted on centile charts and therefore can be detected earlier. In practice too much time should not be spent on trying to define obesity in childhood. A good working rule is if a person looks fat, then he is fat. ${ }^{13}$

1 Taitz, L., and Harris, F., Acta Paediatrica Scandinavica, 1972, 61, 499. Taitz, L., and Byers, H. D., Archives of Disease in Childhood, 1972, 47 257.

3 Hirsch, J., and Han, P. W., Fournal of Lipid Research, 1969, 10, 77

Knittle, J. L., Bulletin of the New York Academy of Medicine, 1971, 47,
Kirsch, J., and Han, P. W. Fournal of Lipid Research, 1969, 10, 77. 579 .

S Abraham, S., and Nordsieck, M., Public Health Reports, 1960, 75, 263.

- Lloyd, J. K., Wolf, O. H., and Whelen, W. S., British Medical fournal, $1961,2,145$.

Eid, E. E., British Medical fournal, 1970, 2, 74.

8 Rabinowitz, D., American fournal of Clinical Nutrition, 1968, 21, 1438.

Salans, L. B., Knittle, J. L., and Hirsch, J., Fournal of Clinical Investigation, 1967, 46, 1112 .

10 Wise, J. K., Hendeler, R., and Felig, P., Science, 1972, 178, 513.

11 Martin, M. M., and Martin, A. L. A., Fournal of Pediatrics, 1973, 82, 192

2 Tanner, J. M.. Whitehouse, R. H., and Takaishi, M., Archives of Disease in Childhood, 1966, 41, 454, and 613 .

18 Heald, F. P., Practitioner, 1971, 206, 223.

\section{Analgesics and the Kidney}

The clinical, pathological, and radiological features of the condition known as analgesic nophropathy are fairly well defined, ${ }^{1}$ and there is little doubt that, since its recognition 20 years ago, it has increased in incidence. ${ }^{2}$ Impressive epidemiological evidence associates the renal lesion with a history of analgesic abuse, ${ }^{3}$ and most physicians now assume that there is a cause-and-effect relationship between the two.

But there is a dearth of controlled observations which might be expected to establish beyond all doubt the ex- istence of a definite relationship. The most convincing observation is that of A. F. Burry and his colleagues, ${ }^{4}$ who reported the results of 507 consecutive necropsies, in 106 of which they found the classical lesions of analgesic nephropathy. Subsequently the patients' drug histories, obtained from their relatives by a different observer, were compared with the necropsy findings, and a clear-cut relationship between analgesic abuse and renal disease was demonstrated. A recent paper by $D$. H. Lawson ${ }^{5}$ based on information collected by the Boston Collaborative Drug Surveillance Program apparently throws some doubt on the existence of this association. Nurses recorded a history of drug intake during the three months preceding the admission of 6,407 patients to medical wards. The patients were allocated to three groups according to whether they took analgesics regularly, occasionally, or not at all, and the incidence of abnormality of the urinary sediment and of diminished renal function in the three groups was compared. Though no significant differences were detected, the work does not allow the conclusion that there is no association between analgesic consumption and renal disease. The principal criticism is that the dose of analgesics consumed was not recorded, and there was no suggestion that even the regular consumers abused these drugs. Furthermore, the duration of the drug history was short, the persistence of the history takers in eliciting a history that is often concealed 6 was not indicated, and only a small minority of the patients consumed analgesics containing phenacetin-a drug which on epidemiological grounds seems the most likely culprit. ${ }^{3}$

Thus the belief that analgesic abuse is associated with chronic renal disease remains unshaken. But controversy still rages over the nature of this relationship. $K$. G. Koutsaimanis and H. D. de Wardener ${ }^{3}$ have reviewed the extensive epidemiological evidence incriminating phenacetin, but the evidence has not found universal support possibly because phenacetin is seldom, if ever, consumed alone; it is usually taken in mixtures with salicylates, codeine, and caffeire. Experiments in man show that salicylates have a distinct effect on the kidney. L. F. Prescott ${ }^{7}$ found an increase in the urinary excretion of tubular epithelial cells which was greater during the administration of aspirin than phenacetin, and recently two groups have detected a reduction in glomerular filtration rate of $10 \%$ after oral ${ }^{8}$ and $30 \%$ after intravenous administration of salicylate. 9 But it is questionable whether these findings have any relationship to the chronic renal damage that is associated with the consumption of several kilograms of analgesics over periods of years.

Numerous studies in rats ${ }^{10}$ have established that, in this animal, salicylates and salicylate-phenacetin mixtures both have a greater propensity to produce papillary necrosis than pheracetin alone and have pointed to salicylates as the principal offenders. But the fact that papillary necrosis is exceedingly rare in people who have abused salicylates alone must make this unlikely. ${ }^{3}$ In addition a high incidence of renal damage has been found in Swedish factory workers ${ }^{11}$ who consumed analgesic mixtures containing phenacetin, phenazone, and caffeine but not salicylates. Priscilla Kincaid-Smith and colleagues ${ }^{12}$ believe that the continued consumption of any analgesic including salicylates will prevent any recovery of renal function in a patient with established analgesic nephropathy and may allow renal function to deteriorate further. But this view too is not universally 